\section{Por um mundo diverso} cultural/linguisticamente: uma reflexão a partir da pedagogia dos multiletramentos

For a culturally/linguistically diverse world: a reflection from the Pedagogy of Multiliteracies

\section{Roziane Keila Grando (iD) (9) \\ kekegrando@yahoo.com.br}

Universidade Estadual do Centro-Oeste - UNICENTRO

\section{Resumo}

Somos frequentemente afetados por discursos de exclusão veiculados nas mídias de massa. E a inclusão acerca dos temas sobre as identidades sociais requer cada vez mais atenção dos professores de línguas. O intuito neste texto é retomar pontos centrais do Manifesto dos Multiletramentos e discutir a necessidade de uma educação linguística, para o contexto brasileiro, a partir dos pressupostos da pedagogia dos multiletramentos, a fim de refletir a respeito do trabalho com as identidades sociais no ensino de línguas. A reflexão está pautada na necessidade de uma perspectiva de letramento que saia de uma formação para o indivíduo, direcionando o envolvimento do sujeito na comunidade, o que é possível com a pedagogia dos multiletramentos, desde que a multimodalidade e a multiculturalidade sejam vistas de maneira conjunta.

\section{Palavras-chave}

Discurso. Diferença. Identidades sociais. Multiletramentos.

\section{Abstract}

We are often affected by discourses of exclusion aired in the mass media. And the inclusion of themes on social identities requires pay attention from language teachers. The aim of this text is claim back to the central points of the multiliteracies manifesto and discuss the need for a linguistic education, for the Brazilian context, based on the assumptions of a pedagogy multiliteracies in order to reflect on the work with social identities in language teaching. The reflection is based on the need for a literacy perspective that comes out of an education for the individual, directing the subject's involvement in the community, which is possible with the pedagogy of multiliteracies, as long as multimodality and multiculturalism are seen together.

\section{Keywords}

Keywords: Discourse. Difference. Social Identities. Multiliteracies.

\section{Introdução}

Quando me sentei para escrever o presente

\section{Linguagẹm Foco}

Revista do Programa de Pós-Graduacão em Linguística Aplicada da UECE

FLUXO DA SUBMISSÃO

Submissão do trabalho: 20/05/2021 Aprovação do trabalho: 14/06/2021 Publicação do trabalho: 28/06/2021

\section{COMO CITAR}

GRANDO, Roziane Keila. Por um mundo diverso cultural/linguisticamente: uma reflexão a partir da pedagogia dos multiletramentos. Revista Linguagem em Foco, v.13, n.2, 2021. p. 86-92. Disponível em: https://revistas.uece.br/index. php/linguagememfoco/article/ view/5600. 
texto, soube pelos noticiários de dois homicídios de jovens em Curitiba-PR. Tudo indica que o suspeito é assassino de homossexuais'. Ao mesmo tempo, na cidade em que resido (Guarapuava-PR), aconteceu o julgamento do caso da advogada Tatiane Spitzner - encontrada morta após supostamente ter caído do $4^{\circ}$ andar de seu apartamento. Conforme as notícias, o réu, seu esposo, foi condenado por homicídio qualificado². Soube ainda da operação policial ocorrida no estado do Rio de Janeiro, que ficou conhecida como "Massacre de Jacarezinho"3. Vejo também, repetidamente, comentários contrários ao acolhimento de venezuelanos, principalmente nas redes sociais ${ }^{4}$. Todas essas situações que citei envolvem vidas e discursos sobre o outro. São discursos que mostram naturalização e intolerância em relação aos que são considerados diferentes ou que são marginalizados e, por isso, envolvem representação e identidades. $\bigcirc$ intuito neste texto é discutir a necessidade de uma educação linguística, para o contexto brasileiro, a partir dos pressupostos da pedagogia dos multiletramentos, a fim refletir a respeito do trabalho com as identidades sociais no ensino de línguas.

\section{Discussão}

Diante desses acontecimentos, que versam acerca das diferenças de gênero, acolhimento (refúgio), e dos casos de violência e tensão em favelas do Rio de Janeiro, é possível perceber que precisamos de leitores e produtores de sentido que tenham um olhar sensível acerca do que acontece em nosso entorno e, ao mesmo tempo, entendam discurso como "[...] uma construção de algum aspecto da realidade, de um ponto de vista particular, sob um ângulo particular, em termos de interesses particulares" (CAZDEN et al.,1996, p. 78, tradução minha).

Para tanto, é preciso educar o entorno, nos termos de Maher (2007), ou seja, é necessário haver uma perspectiva de letramento que saia de uma formação para o indivíduo, direcionando o envolvimento do sujeito na comunidade (GRANDO, 2019). Essa perspectiva não estaria associada somente aos signos lin-

1 Disponível em: https://gl.globo.com/pr/parana/noticia/2021/05/18/morte-de-jovem-de-27-anos-pode-sera-4a-ligada-ao-suspeito-de-assassinar-homossexuais-em-curitiba-e-santa-catarina-diz-policia.ghtml. Acesso em: 20 maio 2021.

2 Disponível em: https://g1.globo.com/pr/campos-gerais-sul/ao-vivo/caso-tatiane-spitzner-juri-popularde-luis-felipe-manvailer-ocorre-nesta-terca-feira-4-em-guarapuava.ghtml. Acesso em: 20 maio 2021.

3 Disponível em: https://brasil.elpais.com/brasil/2021-05-08/mortos-na-chacina-do-jacarezinho-sobempara-29-e-policia-insiste-na-criminalizacao-de-vitimas-sem-provas.html. Acesso em: 16 maio 2021.

4 Disponível em: https://www.correiobraziliense.com.br/mundo/2021/05/4924747-odio-a-imigrantesvenezuelanos-se-espalha-pela-america-latina.html. Acesso em: 16 maio 2021. 
guísticos, mas sim a todas as formas de linguagem em que os discursos são naturalizados e sustentados pois, hoje, cada vez mais, sentidos são construídos por mais de um modo de linguagem: não só pelo verbal, mas também pelo gestual, visual, sonoro etc. E esses discursos são noticiados em forma de textos que funcionam como projetos que têm "maior recrutamento de recursos não verbais" (CAZDEN et al., 1996, p. 79), sendo que, "no fundo, toda produção de sentido é multimodal. Todo texto escrito é também planejado visualmente" (p. 81), discursos que se constituem pelos "padrões de interconexão entre os outros modos" (p. 78).

Nesse sentido, recupero os dois argumentos, citados pelo Manifesto dos Multiletramentos, proposto pelo The New London Group (CAZDEN et al., 1996), os quais envolvem: i) a multiplicidade de canais e de meios de comunicação e ii) a crescente diversidade cultural e linguística diante de uma (nova) ordem global, cultural e institucional emergente.

O grupo de pesquisadores que se reuniu na cidade de Nova Londres, por isso o nome, defende uma perspectiva de educação linguística que verse sobre o pluralismo, no âmbito da cidadania e da vida pessoal, dando atenção à diversidade linguística/cultural. No entanto, mesmo não sendo uma proposta nova (está na agenda das pesquisas em linguística aplicada há 25 anos) ainda é um desafio para muitos educadores, especialmente para quem está em processo de formação continuada.

Os documentos oficiais, tais como a recente Base Nacional Comum Curricular (BNCC), assinalam a importância do trabalho com os multiletramentos, como se percebe no excerto abaixo, retirado do documento, da etapa do ensino médio, de Língua Portuguesa:

[...] do ponto de vista das práticas contemporâneas de linguagem, ganham mais destaque, no Ensino Médio, a cultura digital, as culturas juvenis, os novos letramentos e os multiletramentos, os processos colaborativos, as interações e atividades que têm lugar nas mídias e redes sociais, os processos de circulação de informações e a hibridização dos papéis nesse contexto (de leitor/autor e produtor/ consumidor), já explorada no Ensino Fundamental. Fenômenos como a pós-verdade e o efeito bolha, em função do impacto que produzem na fidedignidade do conteúdo disponibilizado nas redes, nas interações sociais e no trato com a diversidade, também são ressaltados ${ }^{5}$ (BRASIL, 2018, p. 1).

A primeira dúvida que pode surgir ao se discutir a perspectiva da pedago-

5 Disponível em: http://basenacionalcomum.mec.gov.br/abase/\#medio/lingua-portuguesa. Acesso em: 18 maio 2021. 
gia dos multiletramentos está relacionada ao mundo conectado. O trabalho com os multiletramentos não depende necessariamente do acesso à web. É possível utilizar capas de revistas impressas (ou digitais), jornais impressos (ou digitais), anúncios impressos (ou digitais), obras de arte e tantos outros gêneros desde que neles esteja presente a fusão das linguagens. Mesmo em um jornal, em que predomine a modalidade verbal escrita, é possível perceber a presença da multimodalidade ao se observar o funcionamento do modo visual na escolha da tipografia, tamanho da fonte, uso de negrito, itálico etc. Mas, além de trabalhar com a diversidade de modos de linguagem, precisamos estar atentos à diversidade linguística/cultural. Nesse sentido, o mesmo documento traz também a indicação dos multiletramentos, ao tratar do ensino da Língua Inglesa:

\footnotetext{
[...] além dessa visão intercultural e 'desterritorializada' da língua inglesa - que, em seus usos, sofre transformações oriundas das identidades plurais de seus falantes -, consideraram-se também as práticas sociais do mundo digital, com ênfase em multiletramentos ${ }^{6}$ (BRASIL, 2018, p. 1).
}

Com isso, é possível observar que as orientações oficiais guiam um trabaIho a partir dos multiletramentos, mas parece-me, ainda, que o olhar a respeito do que é multicultural se faz, muitas vezes, interpretado pela palavra "diversidade", restringindo-o para as questões linguísticas, como se essas transformações oriundas das identidades plurais de seus falantes (BRASIL, 2018) estivessem relacionadas somente à modalidade linguística em si, deixando-se de lado o contexto cultural envolvido. Não estou dizendo, com isso, que uma abordagem de ensino que reforce o aspecto das diferenças linguísticas não mereça reflexão, mas sim, defendo a necessidade de olhar para o nosso entorno e considerar toda a sua complexidade.

Em contexto brasileiro, como podemos perceber pelos discursos que somos atravessados diariamente, diversidade envolve também os diferentes e suas diferenças. Falta, na minha interpretação, perceber a identidade e a diferença como produção, como relações que acontecem entre diferentes culturas, não olhando essas relações para criar consenso, diálogo ou comunicação, mas, antes, para tratá-las como tensão (GRANDO, 2019). Nesse sentido, a identidade e a diferença "[...] não são elementos passivos da cultura, mas têm que ser constantemente criadas e recriadas. Têm a ver com a atribuição de sentidos ao mundo social e com disputa e luta em torno dessa atribuição" (SILVA, 2014, p. 96).

6 Disponível em: http://basenacionalcomum.mec.gov.br/abase/\#medio/a-area-de-linguagens-e-suastecnologias. Acesso em: 18 maio 2021. 
Essa perspectiva envolve uma disputa de sentidos na "arena" sobre o que é ser mulher, o que é ser homoafetivo, o que é ser um imigrante que busca refúgio no país vizinho, o que é ser brasileiro morador de comunidades, enfim, o que é ser diferente ${ }^{7}$ em uma sociedade que insiste na defesa de uma fixidez e de um ponto de vista "padrão". Conforme advertem os autores no manifesto,

\begin{abstract}
como as pessoas são simultaneamente membros de múltiplos mundos da vida, suas identidades têm múltiplas camadas, que se relacionam de maneira complexa umas com as outras. Nenhuma pessoa é membro de uma única comunidade. Em vez disso, elas são membros de comunidades múltiplas e sobrepostas - comunidades do trabalho, de interesses e afiliações, de etnias, de gênero, e assim por diante (KALANTZIS, 1995 apud CAZDEN et al., 1996, p. 71).
\end{abstract}

Assim sendo, ao se expandir a compreensão sobre o ensino de línguas pautado nos multiletramentos, o Grupo de Nova Londres chama a atenção para o fato de que as vivências dos estudantes não envolvem um trabalho somente com a multimodalidade ou somente com a multiculturalidade. Esses dois pontos-chave funcionam juntos. Para isso, como professores de línguas, precisamos trazer constantemente os temas da vida pública em nossas aulas, de maneira que coloque o aluno como produtor de significados, como um designer que se engaja em atividades semióticas de leitura e produção dos mais variados gêneros. Por isso, o termo-chave da pedagogia dos multiletramentos é o design.

De acordo com os autores do manifesto, a escolha da palavra design ocorreu em detrimento de gramática, não como um conjunto de regras autoritárias, mas porque a palavra design permitia a ambiguidade que lhes interessava: referindo-se tanto ao processo quanto ao produto. Conforme Pinheiro (2016, p. 1), para contemplar as três dimensões da vida social,

\begin{abstract}
o grupo propôs um conceito-chave da pedagogia dos multiletramentos: o design uma (re)apropriação do termo 'design' da dimensão profissional (mundo do trabaIho) para as outras duas dimensões da vida social (pessoal e de participação cívica), na tentativa de colocá-las também sob escrutínio de interpretações e ressignificações possíveis em diferentes contextos, tornando-as suscetíveis ao dinamismo, interesse pessoal e capacidade de transformação.
\end{abstract}

Ao lidar com os diferentes modos de linguagem e as diferenças sociais, vejo a necessidade do entendimento de que o combate à diferença se dá entre discursos, tanto os discursos que representam a hegemonia quanto os que representam as minorias. Para isso, precisamos ensinar o questionamento sobre

7 Sem esquecer de questões como surdez, raça e etnia etc., que também entram nesse bojo. 
os discursos manipuladores, sendo favorável à multiplicidade (LAURETIS, 1994). A educação linguística que a pedagogia dos multiletramentos prega necessita ser ressignificada para o nosso contexto, pensando em sujeitos produtores de significados que não apaguem ou negligenciem as identidades nem os múltiplos mundos da vida e que reconheçam "o valor de cada voz individual" (HOOKS, 2013, p. 58), pois é no co-engajamento do designing que as pessoas transformam as suas relações umas com as outras e, dessa forma, transformam-se (CAZDEN et al., 1996).

\section{Considerações finais}

A partir do momento em que as discussões aqui sinalizadas entram na agenda do ensino de línguas, os envolvidos no processo (professores, alunos e comunidade escolar) precisam de disposição para o entendimento de que "abordar o ensino a partir de um ponto de vista que inclua uma consciência de raça, do sexo e de classe social tem suas raízes, muitas vezes, no medo de que a sala de aula se torne incontrolável, que as emoções e paixões não sejam mais represadas" (HOOKS, 2013, p. 55). Como afirma a autora, nós, docentes, precisamos entrar em sala partindo de um consenso de que é necessário construir uma comunidade e, como nos mostra o manifesto, essas comunidades são múltiplas e sobrepostas, entendendo que viver com a diferença é saudável, porque com isso poderemos estabelecer um clima de abertura e um sentimento de comunidade que deem a "sensação de um compromisso partilhado e um bem comum que nos une" (HOOKS, 2013, p. 58). Claro que o que vai nos unir é o desejo de aprender e de receber de forma ativa o conhecimento, intensificando nosso desenvolvimento intelectual e a nossa capacidade de viver plenamente em um mundo diverso cultural e linguisticamente.

\section{Referências}

BRASIL. Ministério da Educação. Base Nacional Comum Curricular. Brasília, 2018.

CAZDEN, C. et al. A Pedagogy of Multiliteracies: Designing Social Futures. Harvard Educational Review, v. 66, n. 1, p. 60-92, Spring 1996. Disponível em: http://newarcproject.pbworks.com/f/Pedagogy+of+Multiliteracies_New+London+Group.pdf. Acesso em: 02 maio 2021.

GRANDO, R. K. Investigações sobre leitura multimodal crítica na formação continuada de professores de línguas. 2019. 261 f. Tese (Doutorado em Linguística Aplicada) - Instituto de estudos da Linguagem, Universidade Estadual de Campinas, Campinas, 2019. Disponível em: http:// repositorio.unicamp.br/jspui/bitstream/REPOSIP/335614/1/Grando_RozianeKeila_D.pdf. Acesso em: 20 maio 2020. 
HOOKS, Bell. Ensinando a transgredir: a educação como prática da liberdade. Ed. São Paulo, 2013.

LAURETIS, Teresa De. A tecnologia do gênero. Tradução de Suzana Funck. In: HOLLANDA, Heloisa (Org.). Tendências e impasses: o feminismo como crítica da cultura. Rio de Janeiro: Rocco, 1994. p. 206-242.

PINHEIRO, Petrilson Alan. Sobre o manifesto "A pedagogy of multiliteracies: designing social futures" - 20 anos depois. Trab. linguist. apl., Campinas, v. 55, n. 2, p. 525-530, ago. 2016. Disponível em: http://www.scielo.br/scielo.php?script=sci_arttext\&pid=S0103-18132016000200525\&lng=en\&nrm=iso. Acesso em: 20 maio 2021.

SILVA, T. T. da. A produção social da identidade e da diferença. In: Tomaz Tadeu da Silva (org.) Identidade e diferença: a perspectiva dos Estudos Culturais.15. ed. Petrópolis, RJ: Vozes, 2014.

\section{Sobre a autora}

Roziane Keila Grando - Doutora em Linguística Aplicada pela Universidade Estadual de Campinas (Unicamp). Professora substituta do curso de Letras da Universidade Estadual do Centro-Oeste (UNICENTRO) - Guarapuava-PR. E-mail: kekegrando@yahoo.com.br. Lattes:http://lattes.cnpq.br/8778811156995344. OrclD:https://orcid.org/0000-0001-62598878. 